\title{
Home Telemonitoring in Patients With Chronic Heart Failure
}

\author{
A Chance to Improve Patient Care?
}

Silke Schmidt, Andreas Schuchert, Thomas Krieg, Michael Oeff

\section{SUMMARY}

Background: Telemonitoring can improve the medical care, quality of life, and prognosis of chronically ill patients. This review article summarizes the current status of health services research on telemonitoring, focusing on patients with chronic congestive heart failure.

Method: The Medline database was selectively searched for articles appearing from June 2001 to May 2008, with an emphasis on randomized, controlled trials.

Results: The available scientific data on vital signs monitoring are limited, yet there is evidence for a positive effect on some clinical endpoints, particularly mortality. Nonetheless, any possible improvement of patientreported outcomes, such as the quality of life, still remains to be demonstrated.

\section{Conclusions: The data suggest that telemonitoring is} effective, yet there is no evidence for superior outcomes with any particular model of care incorporating telemonitoring (i.e., monitoring of vital signs versus structured telephone monitoring). A valid criticism is that the individual components of home telemonitoring have not yet been separately tested in order to compare their individual effects.

\section{Cite this as: Dtsch Arztebl Int 2010; 107(8): 131-8} DOl: 10.3238/arztebl.2010.0131

Lehrstuhl Gesundheit und Prävention, Ernst-Moritz-Arndt Universität Greifswald: Prof. Dr. phil. Schmidt, Dipl-Psych. Krieg

Friedrich-Ebert-Krankenhaus Neumünster, Medizinische Klinik: Prof. Dr. med. Schuchert

Städtisches Klinikum Brandenburg, Innere Medizin: Prof. Dr. med. Oeff
elemonitoring is credited with the potential to improve the medical care, quality of life, and prognosis of chronically ill patients. The generic term "telemonitoring" covers a wide spectrum of clinical approaches to the electronic transmission of biological data or patients' own reports on themselves to the treating physician. In some applications the information is collected by one or more devices that monitor the desired parameters at regular intervals and sends them to the physician either automatically or when the patient triggers data transmission. Typical biological signals measured in this way are heart rate, blood pressure, ECG changes, oxygen saturation, body weight, respiratory rate, and body temperature. The second possibility is the transmission by telephone of verbal selfreports and/or pictures of the patient. Telemonitoring may be continuous or intermittent, usually eventtriggered, and the choice of data to be collected should be determined by the clinical problem and the circumstances of the individual patient (14). With particular reference to various cardiac diseases, the clinical indications, the clinical benefit, and the technical preconditions for telemonitoring have been clearly delineated in the German-speaking countries $(13,18,23, \mathrm{e} 14)$.

One important use of telemonitoring is to improve the observation of chronically ill patients between inpatient or outpatient contacts with their doctors, or in their home environment. This implies long-term monitoring. More frequent collection of data is intended to enhance evaluation of the patient's condition, enabling the treating clinician to detect any deterioration at an early stage and to combat it with specific measures, thus potentially avoiding hospital admission.

Telemonitoring can also induce other effects and thus influence the quality of care. One mechanism of action in this respect could be improved selfmanagement by chronically ill patients. Potential favorable consequences include greater compliance with prescribed medication.

The recent developments and applications of telemonitoring techniques have been principally driven by the medical industry. This has led to a large number of very innovative solutions that could meet the abovementioned criteria. This rapid technical progress offers many opportunities for improvements in patient care. It 
BOX

\section{Criteria for success of telemonitoring}

- Clinical criteria

- Overall mortality, rehospitalization rate

- Patient-related criteria

- Quality of life, acceptance

- Physician-related criteria

- Acceptance, workload

- Health-economic benefits, costs of intervention

must not be forgotten, however, that although observational studies may verify the technical and clinical feasibility of innovative systems, they do not demonstrate their clinical efficacy in the sense of evidencebased medicine. Randomized controlled trials (RCTs) are mandatory before such methods can be widely applied in routine patient care.

This review therefore sets out to describe whether and how the various telemonitoring procedures have improved patient care to date. It is confined to patients with chronic heart failure, because this disease has been more widely investigated than any other and thus more data are available. Furthermore, we look into the effects of telemonitoring for various indications on patient self-management, specifically medication intake, an important and frequent criterion for the success of selected telemonitoring procedures with regard to treatment compliance by the patient. Since the majority of procedures under the heading of "telemonitoring" aim to be complementary, quality-enhancing techniques (21), it does not suffice to demonstrate their equivalence to existing modes of care; rather, they must display added therapeutic value.

\section{Methods}

We investigated a selection of RCTs in the two fields defined above. These studies were chosen on the basis of selected criteria of health services research (Box) and identified by searching Medline and Embase publications from the period June 2001 to May 2008 (search terms: telemedicine OR telemonitoring OR home monitoring AND outcome research OR health service research OR clinical outcome OR cost analysis OR patient OR outcome acceptance OR quality of life). Existing meta-analyses of randomized studies were included $(5,6)$, as were selected evidence reports and descriptive reviews (3, e13, e16, e17). The literature search was selective in that it was restricted to studies that embraced the criteria of health services research listed in the Box. With regard to the application of telemonitoring in Germany, we look at recent clinical studies from the German-speaking area. Two studies published in 2009 describe the latest findings (e22, e23).

\section{Results}

\section{Multidisciplinary meta-analyses and reviews}

An evidence analysis carried out on behalf of the Agency for Healthcare Research and Quality, a body affiliated to the US Department of Health and Human Services, was published in 2006. This multidisciplinary report evaluated not only telemonitoring techniques, but also other telemedical procedures, such as telediagnosis, in which the conventional direct, face-to-face doctor-patient contact is replaced. Hersh and colleagues came to the conclusion that there is good evidence for the efficacy of telemonitoring for systems in which primarily verbal information is conveyed (e.g., video conferences) (e8). At that time (studies published up to December 2004), the data were too limited for adequate evaluation of the clinical value of other telemonitoring procedures, particularly the transmission of vital signs, in diagnosis and therapy. More data have been gathered in the meantime. Numerous RCTs have appeared, and we examined six descriptive reviews and three systematic meta-analyses on heart failure (Table). The analyses found evidence for various trends. For example, telemonitoring procedures seem to be more effective in cardiac diseases than in other chronic illnesses. With one exception, however, they do not permit definite conclusions on the value of teletransmission of vital signs (e16).

\section{Studies on home telemonitoring of chronic heart failure}

The majority of RCTs (13 of 19) in patients with chronic heart failure have exclusively employed structured telephone monitoring, with symptoms registered at defined intervals after hospital discharge $(1,7,8,10$, $11,15,16,19,20,24$, e2, e4, e5). Only a very small number of RCTs have investigated the value of monitoring such widely varying vital signs as heart rate, weight, and blood pressure (2, 9, 12, 15, 25, e2, e20). The ground-breaking study by Cleland and colleagues (7), together with the same group's review in the $B M J$, shows an advantage of telemonitoring over conventional management with regard to overall mortality and rehospitalization rate; no difference was observed between telephone monitoring and monitoring of vital signs (6).

Effect on mortality and rehospitalization-Both monitoring of vital signs and telephone monitoring achieved a 20\% reduction (95\% confidence interval: $8 \%$ to $31 \%$ ) in overall mortality over an observation period of 3 to 16 months in patients with NYHA class I to IV heart failure (6). No difference was demonstrated between structured telephone monitoring and vital signs monitoring. The review by Chaudhry et al. showed a reduction in mortality as high as $40 \%$ (5). This analysis embraced only six studies with positive findings $(2,7,10,11,15,19)$. At the same time, studies with any hint of selection were excluded from overall consideration $(8,12,15,20)$, although none of them showed any advantage for telemonitoring. A recently published meta-analysis that also included cohort studies and confirmed the findings of the reviews from 
Overview of reviews on telemonitoring of heart failure $*^{1}$

\begin{tabular}{|c|c|c|c|c|c|}
\hline Author(s) & Year & Topic of review & Focus & Method & Findings \\
\hline $\begin{array}{l}\text { Clark } \\
\text { et al. }\end{array}$ & 2007 & $\begin{array}{l}\text { Telemonitoring or structured } \\
\text { telephone programs for patients } \\
\text { with heart failure; systematic review } \\
\text { and meta-analysis }\end{array}$ & $\begin{array}{l}\text { Clinical, } \\
\text { costs, } \\
\text { patient acceptance, } \\
\text { RCTs }\end{array}$ & $\begin{array}{l}\text { Analytic- } \\
\text { systematic }\end{array}$ & $\begin{array}{l}\text { Overall mortality reduced ( } 20 \%) \text {; hospitalization } \\
\text { reduced in } 14 \text { RCTs; three of six trials showed } \\
\text { improvement in quality of life, three of four a cost } \\
\text { benefit }\end{array}$ \\
\hline $\begin{array}{l}\text { Chaudhry } \\
\text { et al. }\end{array}$ & 2007 & $\begin{array}{l}\text { Telemonitoring for patients with } \\
\text { heart failure; systematic review }\end{array}$ & $\begin{array}{l}\text { Clinical, } \\
\text { costs }\end{array}$ & $\begin{array}{l}\text { Analytic- } \\
\text { systematic }\end{array}$ & $\begin{array}{l}\text { Six of nine studies showed reductions in hospital- } \\
\text { ization rates ( } 14 \% \text { to } 55 \%) \text { and mortality ( } 40 \% \text { to } \\
56 \%) \text {; three negative studies were analyzed with } \\
\text { regard to patient bias (low or high risk) }\end{array}$ \\
\hline $\begin{array}{l}\text { Klersy } \\
\text { et al. }\end{array}$ & 2009 & $\begin{array}{l}\text { Meta-analysis of heart failure } \\
\text { patients }\end{array}$ & $\begin{array}{l}\text { Clinical, } \\
\text { costs, } \\
\text { RCTs, } \\
\text { cohort studies }\end{array}$ & $\begin{array}{l}\text { Analytic- } \\
\text { systematic }\end{array}$ & $\begin{array}{l}\text { Significant reduction in mortality; significant } \\
\text { reduction in hospitalization rate only in cohort } \\
\text { studies; marked heterogeneity of results }\end{array}$ \\
\hline $\begin{array}{l}\text { Martínez- } \\
\text { Fernández } \\
\text { et al. } .^{2}\end{array}$ & 2006 & $\begin{array}{l}\text { Systematic literature review of } \\
\text { home monitoring in patients with } \\
\text { heart failure }\end{array}$ & $\begin{array}{l}\text { Diverse } \\
\text { outcomes }\end{array}$ & $\begin{array}{l}\text { Descriptive- } \\
\text { systematic }\end{array}$ & $\begin{array}{l}\text { Sixteen of } 42 \text { studies showed a trend towards } \\
\text { shorter hospital stay; three RCTs showed } \\
\text { reduction in mortality }\end{array}$ \\
\hline $\begin{array}{l}\text { Pare } \\
\text { et al. }\end{array}$ & 2007 & $\begin{array}{l}\text { Systematic review of home tele- } \\
\text { monitoring for chronic illnesses }\end{array}$ & $\begin{array}{l}\text { Clinical, } \\
\text { costs }\end{array}$ & $\begin{array}{l}\text { Descriptive- } \\
\text { systematic }\end{array}$ & $\begin{array}{l}\text { The effect of telemonitoring is more uniform in } \\
\text { cardiological and pulmonary diseases than in } \\
\text { diabetes and high blood pressure }\end{array}$ \\
\hline $\begin{array}{l}\text { Barlow } \\
\text { et al. }\end{array}$ & 2007 & $\begin{array}{l}\text { Systematic review of the advantages } \\
\text { of home telemonitoring of elderly } \\
\text { patients and those with long-term } \\
\text { symptoms }\end{array}$ & $\begin{array}{l}\text { Clinical, } \\
\text { costs, } \\
\text { RCTs }\end{array}$ & $\begin{array}{l}\text { Descriptive- } \\
\text { systematic }\end{array}$ & $\begin{array}{l}\text { In various diseases, } 68 \text { RCTs ( } 29 \% \text { CHF) showed } \\
\text { that telemonitoring of vital signs was the most } \\
\text { promising approach; a nursing-based follow-up } \\
\text { also showed benefits }\end{array}$ \\
\hline Schmidt & 2007 & $\begin{array}{l}\text { Telemedicine and quality of life: } \\
\text { review }\end{array}$ & $\begin{array}{l}\text { Patients' } \\
\text { subjective } \\
\text { outcomes }\end{array}$ & Descriptive & $\begin{array}{l}\text { Currently there is no proof of a predominant } \\
\text { benefit of telemonitoring over other models of } \\
\text { patient care regarding quality of life }\end{array}$ \\
\hline
\end{tabular}

2007 points to the heterogeneity of the studies performed (e23). Whether the favorable effect on mortality persists in the long term is questioned by the REMADHE study, which employed structured telephone monitoring (e3). This study had the longest mean study duration to date $(2.5 \pm 1.8$ years $)$ and shows no differences in mortality between the intervention group and the control group.

Judged by the criterion of rehospitalization rate, four studies showed that morbidity was reduced significantly by telemonitoring compared with standard aftercare $(3,5,7, \mathrm{e} 4)$. The rate of rehospitalization due to signs of heart failure was reduced by $21 \%$ (95\% confidence interval: $11 \%$ to $31 \%$ ). There were no significant effects on overall rehospitalization rate, recorded in eight studies.

Biometric analyses of the effects on quality of life are summarized graphically in Figures 1 and 2, the effects on mortality in Figure 3.

Patient-related criteria: quality of life-To date, improvement in quality of life has not been a primary endpoint of telemonitoring studies. Two descriptive reviews each evaluated six RCTs; in each case, three trials showed a significant advantage of telemonitoring over standard care and three showed no advantage (6,
21). On closer inspection, however, the increase was not in overall quality of life, but in selected subscales (e.g., bodily function), and long-term effects were often not registered. In one single study the long-term effects were recorded using a heart failure-specific quality of life questionnaire (e20) and significant improvements were demonstrated.

Health-economic benefits-The health-economic potential of telemonitoring has been highlighted in numerous studies and demonstrated in seven RCTs (6). The benefits are difficult to assess, however, because only 4 of the 14 RCTs included the cost of the intervention in the cost-benefit analyses. From their review, for example, Chaudhry and colleagues (5) derive valid specific intervention costs, for the USA market, of ca. 1600 dollars for low-threshold and over 8000 dollars for more complex programs, indicating wide overall variability of costs. A few studies have reported healtheconomic benefits, but other authors have found higher costs (3, e13).

Acceptance of home monitoring by patients-Randomized studies show very high (90\% to 95\%) acceptance of telemonitoring by patients. In the great majority of studies telemonitoring had no negative influence on patient satisfaction, but even 
Effect strength and CI

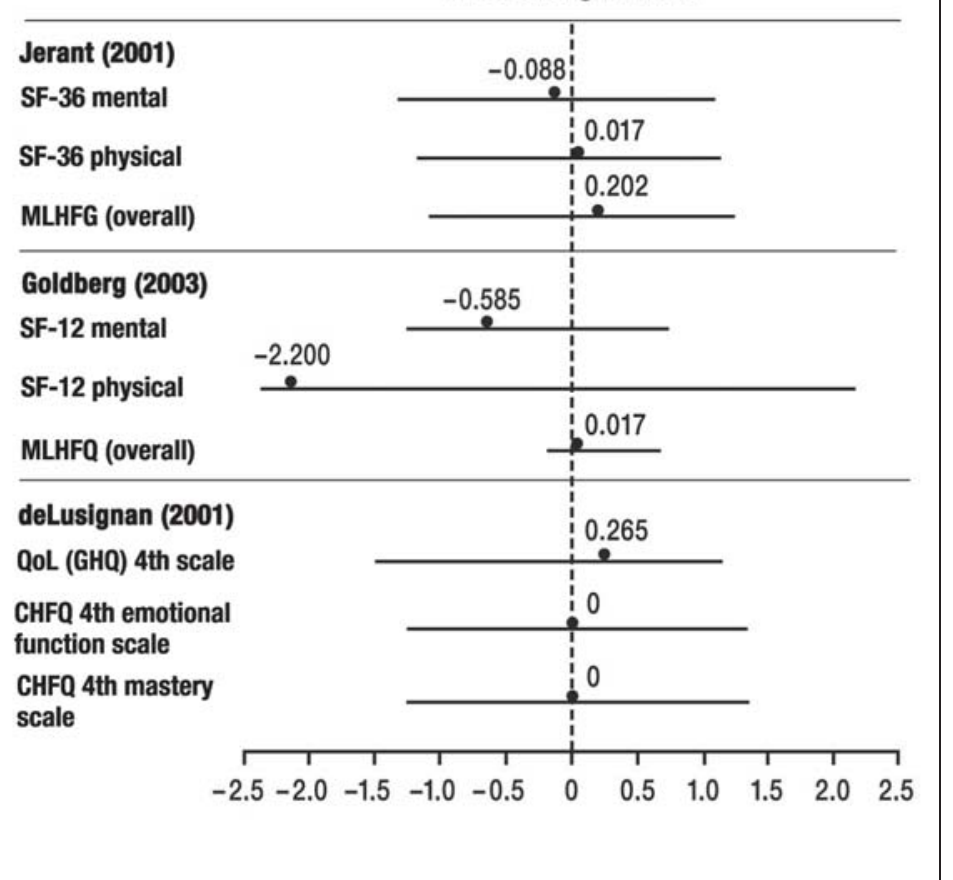

Monitoring of vital signs versus standard care. SF-36/SF-12, 36-item/12-item ShortForm Health Survey (self-assessment questionnaire on health status); MLHFQ, Minnesota Living with Heart Failure Questionnaire; $\mathrm{Q} \mathrm{L}(\mathrm{GHQ})$, quality of life measured using the General Health Questionnaire; CHFQ, Chronic Heart Failure Questionnaire (a questionnaire on chronic heart failure that has numerous subscales; considered here are the fourth emotional function scale and the fourth mastery scale); $\mathrm{Cl}$, confidence interval

improved it (e12, e14, e17). In contrast, willingness to participate in telemonitoring was only $50 \%$ to $60 \%$ in an indication study that also investigated those who refused or discontinued monitoring (22). This study shows that acceptance is partly confounded with the criteria for meeting the goals of telemonitoring. Longterm analyses of telemonitoring have also found acceptance of only around 50\% (e3), although no longterm studies of the monitoring of vital signs have yet been published.

Acceptance by clinicians and influence on doctor-patient relationship-The acceptance of telemonitoring applications by physicians has not yet been examined in any published controlled studies. This seems to be a central aspect, because in the context of other steering mechanisms in the health care system many physicians fear that the introduction of telemedicine, in particular, could fundamentally alter their clinical activity and the relationship of trust between doctor and patient; they are apprehensive about the effect of the employment of electronic media on their clinical work (e17). From the few existing studies on the influence of telematics on the doctor-patient relationship it can in principal be deduced that the majority of analyses show a stable or even improved relationship between clinician and patient (21). To date, however, one essential parameter has not been investigated in process analyses, namely the influence of telemedical methods on diagnostic decision-making and the physician's perceptions, although research on electronic diagnostic decision systems has yielded suggestions that diagnostic decision-making is improved. There are merely indications, from exploratory studies focused on cognitive processes, that considering symptoms in the framework of an electronic database rather than direct narrative led to a diagnostic strategy that took more account of details (21). A further point is whether the relationship to other doctors in the chain of care remains unaffected.

Significance of telemonitoring for patient compliance-Despite the numerous studies on clinical endpoints, the mechanisms of action of telemonitoring still remain unexplained. One of the suggested mechanisms is increased compliance with treatment, e.g., improved intake of medication or closer adherence to the treatment plan. In the great majority of RCTs that investigated compliance, increased compliance of heart failure patients with medication intake and alterations in 


\section{FIGURE 2}

Effect strength and CI

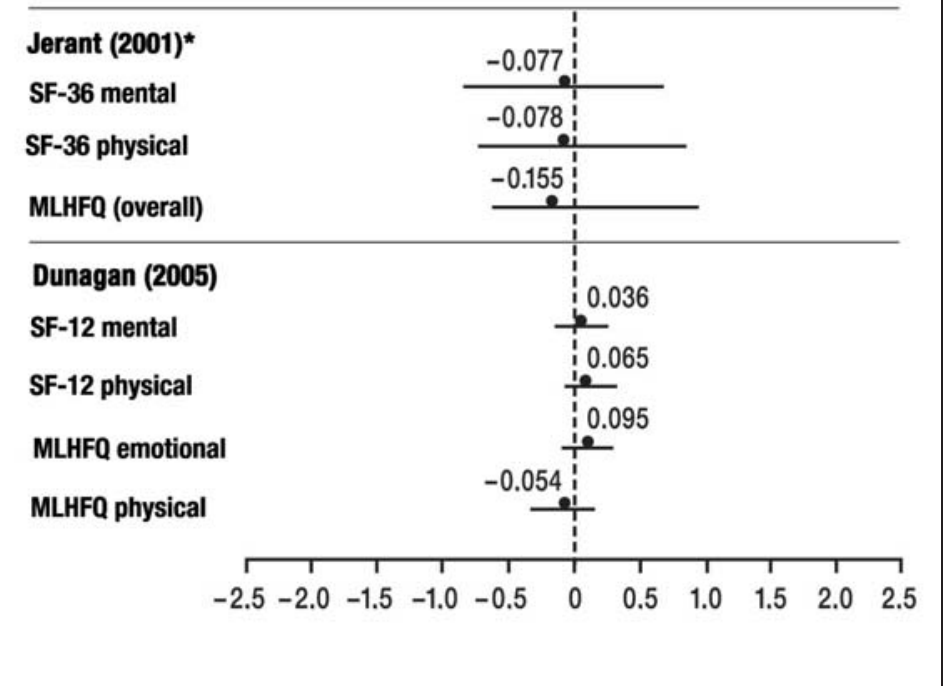

Telephone intervention versus standard care. SF-36/SF-12, 36-item/12-item ShortForm Health Survey (self-assessment questionnaire on health status); MLHFQ, Minnesota Living with Heart Failure Questionnaire; $\mathrm{Cl}$, confidence interval; * Comparison: Telephone support versus usual care

medication was demonstrated (9, 22, e17). For example, in one study it was shown that compliance improved by ca. $40 \%$ with the introduction of a system for medication intake (22). However, no (comparative) analysis of these intermediary mechanisms of action on one hand and treatment endpoints on the other has yet been conducted.

Telemonitoring of electrical implants-The implantation of electrical devices is a further treatment option for patients with chronic heart failure. Because of the increased risk of sudden cardiac death, patients with a left ventricular ejection fraction reduced to $<35 \%$ have benefited from an implantable cardioverter defibrillator (ICD). Moreover, the symptoms and prognosis of highly symptomatic heart failure patients with systolic dysfunction and left bundle block are improved by the implantation of a cardiac resynchronization therapy (CRT) system. Telemonitoring is intended to simplify the use of these devices in that the implants perform aftercare automatically or under the patient's control and the findings are validated electronically by the physician. The cost efficiency of aftercare should thus be enhanced. Various telemedical applications have become established in this context, such as self- monitoring, remote monitoring, and retro-monitoring (e7). Several manufacturers of implantable devices have offered such applications in recent years (e6).

Observational studies of these applications show that technically and clinically, the various systems have been developed to the point that they allow extensive or even complete implant aftercare without hospital visits. The most comprehensive such study involved over 11000 patients on home monitoring and more than 3 million data retrievals (17). In the first randomized trial, events necessitating treatment were detected earlier in the telemedicine group than in the control group (e22). The REFORM study looked, for example, at primary prevention and showed that telemedical followup of ICD patients reduced patient visits distinctly, by $63.2 \%$, compared with conventional inquiry and that overall there was an average saving of 712.31 euros per patient per year (e21).

\section{Discussion}

In summary, the data on home monitoring from randomized studies are still sparse, presumably because home monitoring is still undergoing development, but new observational studies altogether show promising effects. 
Vital signs monitoring

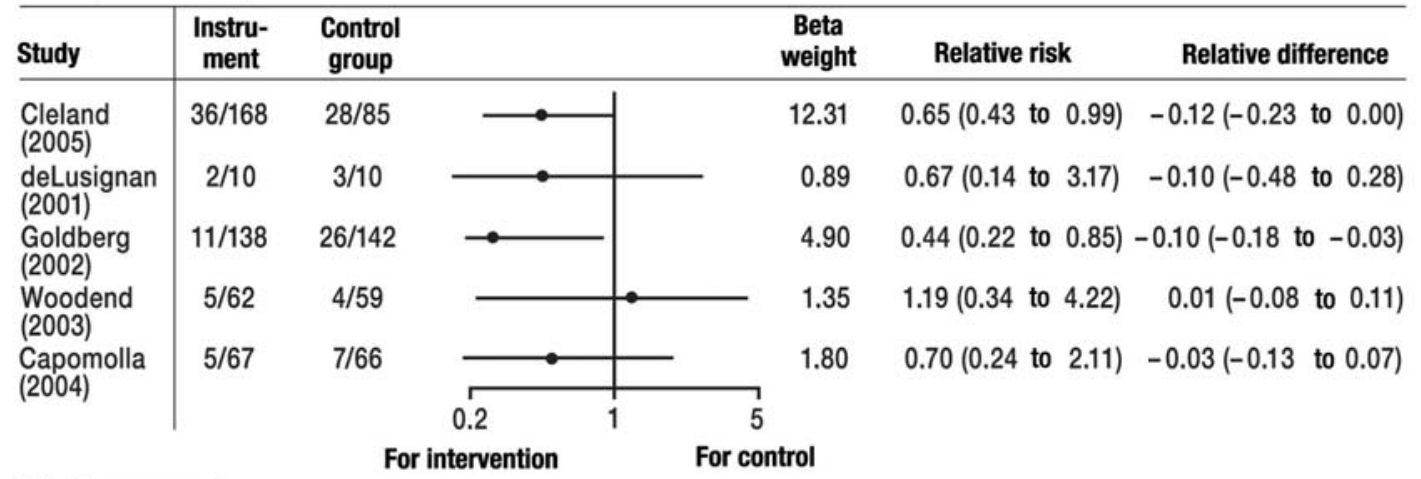

Telephone support

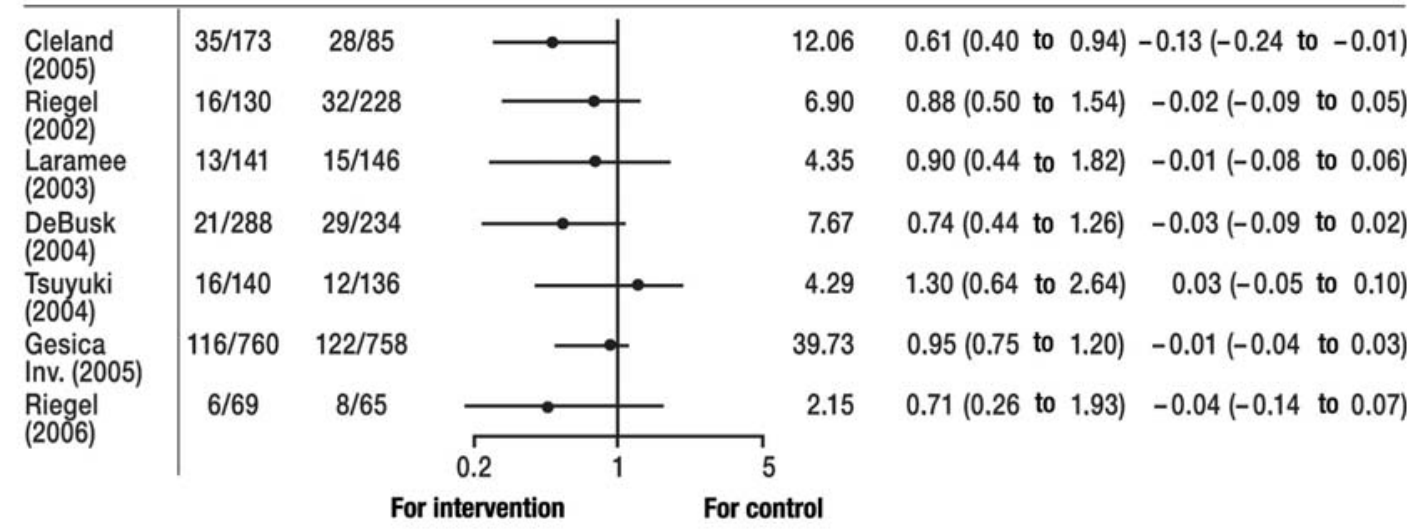

Overview of the effects of telemonitoring on mortality. Odds ratios between intervention group and control group

Telemonitoring has the potential to improve patient care in many ways. Prominent among the study findings are the indications of a ca. $20 \%$ reduction in mortality of patients with heart failure $(5,6)$. Considerable improvements have already been achieved precisely in the area of vital signs monitoring, as documented by several observational studies (17).

Certainly these findings need to be confirmed in carefully planned studies. It has to be acknowledged that to date the majority of studies relate to telephone monitoring and so far no added value has been proved for monitoring of vital signs $(7,15)$. This prompts the question of whether it might be the intense effort put into the followup that produces the clinical benefit and what constitutes the added value of vital signs monitoring.

Fundamentally the distinction between telephone monitoring and monitoring of vital signs is too crude to permit investigation of the decisive mechanisms of action of telemonitoring that influence both the objective and the subjective findings. The majority of definitions with regard to telemonitoring, as well as the developmental trend in the products on the market, relate not to telephone monitoring, however, but to vital signs monitoring, so that a definition is required of various developmental stages with different mechanisms of action, together with an evaluation of the consequences that is oriented on these stages (e18, e19).

In health-economic terms, the reduction in the number of patients admitted to the hospital for treatment of heart failure shows the essential efficacy of the telemonitoring concept. The effectiveness of telemonitoring in the framework of patient care as a whole remains questionable, however, as long as the absolute numbers of admissions do not differ statistically significantly between the intervention group and the control group. There may be various reasons for this, e.g., that the number of admissions due to heart failure is so small that the reduction had no significant effect on total hospital admissions. Other effects may have occurred, resulting in patients being admitted for other reasons. The question cannot be answered conclusively from the data published hitherto. Compared with the diagnosis and treatment of heart failure, the data on other diseases are utterly inadequate.

For the future, indication studies are required that investigate the influence of specific user groups. This is 
necessary, for example, because two meta-analyses excluded studies on specific sociocultural groups (22). Moreover, across the whole of Germany there is a lack of epidemiologically oriented health services research into this topic. Linder and colleagues (e11) investigated how, for instance, the use of electronic medical records actually affected the quality of patient care. Another study in the USA revealed that only $10 \%$ to $20 \%$ of all doctors who had started using electronic medical records had also taken advantage of more complex telemedical functions (e10). The availability of the technology and the degree of actual use are widely divergent.

There is a fundamental requirement for health services research to find out more about the putative mechanisms of action of telemonitoring:

- What are the mechanisms of action of telemonitoring? Is it the increase in knowledge on the part of the doctor? The frequency of data retrieval or "patient contacts"? The improved compliance with treatment?

- How do the roles of the participating physicians vary, and what modes of communication actually occur?

- What are the long-term effects of telemonitoring, and can more durable acceptance be achieved with monitoring of vital signs than with telephone monitoring?

Multidimensional criteria and depth analyses are required particularly with regard to the doctor-patient relationship, the satisfaction of doctor and patient with the system, and patient's quality of life. Despite the replicable, hitherto only generically interpretable indications of the clinical significance of telemonitoring, the evidence of improvement in quality of life is inconclusive so far (21), especially given that the majority of all telemonitoring approaches count improvement in quality of life as one of the primary criteria of success. In addition, the essential nature of telemonitoring leads

\section{KEY MESSAGES}

- The generic term "telemonitoring" embraces widely differing treatment concepts, from monitoring of vital signs to structured telephone follow-up.

- Telemonitoring exercises an influence on the prognosis of diseases by reducing mortality, although strong effects have so far been found only in meta-analyses.

- There is not yet any adequate evidence of improvement of patients' quality of life by telemonitoring.

- Health-economic analyses have seldom included the costs of the intervention.

- The mechanisms of action of telemonitoring have not yet been demonstrated: Is it the patient's compliance that increases, or the doctor's knowledge? to distance between doctor and patient (e14, e17). For this reason, this field represents a major challenge not only for clinical research but also for research in psychosocial medicine, since the consequences of this distance for both doctor and patient can have widereaching effects on clinical decision-making and patient outcome.

\section{Conflict of interest statement}

The authors declare that no conflict of interest exists according to the guidelines of the International Committee of Medical Journal Editors.

Manuscript submitted on 2 March 2009, revised version accepted on 10 June 2009.

Translated from the original German by David Roseveare.

\section{REFERENCES}

1. Barth $V$ : A nurse-managed discharge program for congestive heart failure patients: outcomes and costs. Home Health Care Management \& Practice 2001; 13: 436-43.

2. Benatar $D$, et al.: Outcomes of chronic heart failure. Arch Intern Med 2003; 163: 347-52

3. Bocchi EA, et al.: Long-term prospective, randomized, controlled study using repetitive education at six-month intervals and monitoring for adherence in heart failure outpatients: The REMADHE Trial. J Am Med Inform Assoc 2002; 9: 49-62.

4. Braunschweig $F$, et al.: Can monitoring of intrathoracic impedance reduce morbidity and mortality in patients with chronic heart failure? Rationale and design of the Diagnostic Outcome Trial in Heart Failure (DOT-HF). Eur J Heart Fail 2008; 10: 907-16.

5. Chaudhry S, et al.: Telemonitoring for patients with chronic heart failure: a systematic review. J Card Fail 2007; 35: 56-62.

6. Clark RA, et al.: Telemonitoring or structured telephone support programmes for patients with chronic heart failure: systematic review and meta-analysis. BMJ 2007; 334-442.

7. Cleland JG, et al.: Noninvasive home telemonitoring for patients with heart failure at high risk of recurrent admission and death: the Trans-European Network-Home-Care Management System (TEN-HMS) study. J Am Coll Cardiol 2005; 45: 1654-65.

8. DeBusk RF, Miller NH, Parker KM: Care management for low-risk patients with heart failure: a randomized, controlled trial. Ann Intern Med 2004; 141: 606-13

9. De Lusignan S: Compliance and effectiveness of 1 year's home telemonitoring. The report of a pilot study of patients with chronic heart failure. Eur J Heart Fail 2001; 3: 723-30.

10. Dunagan WC, et al.: Randomized trial of a nurse-administred, telephone-based disease management program for patients with heart failure. J Cardiac Failure 2005; 11: 358-65.

11. GESICA Investigators: Randomized trial of telephone intervention in chronic heart failure: DIAL trial. BMJ 2005; 331: 425.

12. Goldberg LR, et al.: Randomized trial of a daily electronic home monitoring system in patients with advanced heart failure: the Weight Monitoring in Heart Failure (WHARF) trial. Am Heart J 2003; 146: 705-12.

13. Handschu R, Oeff M, Ernstberger A: Telemedizin. Notfallmedizin update 12, 2008; 3: 357-66.

14. Helms TM, Pelleter JT, Ronneberger DL: Telemedizinische Betreuung chronisch herzinsuffizienter Patienten am Beispiel des telemedizinischen Patientenbetreuungs- und -schulungsprogramms „Telemedizin fürs Herz". Herz 2007; 32: 623-39.

15. Jerant AF, Azari R, Nesbitt TS: Reducing the cost of frequent hospital admissions for congestive heart failure: a randomized trial of a home telecare intervention. Medical Care 2001; 39: 1234-45. 
16. Laramee AS, Levinsky SK: Case management in a heterogeneous congestive heart failure population. Arch Intern Med 2003; 163: 809-17.

17. Lazarus A: Remote, wireless, ambulatory monitoring of implantable pacemakers, cardioverter defibrillators, and cardiac resynchronization therapy systems: analysis of a worldwide database. Pacing Clin Electrophysiol 2007; 30: Suppl 1: 2-12.

18. Oeff M, et al.: EKG-Monitoring. Herzschr Elektrophys 2008; 19: $137-45$.

19. Riegel B, et al.: Effect of a standardized nurse case management telephone intervention on resource use in patients with chronic heart failure. Arch Intern Med 2002; 162: 705-12.

20. Riegel B, et al.: Randomized controlled trial of telephone case management in Hispanics of Mexican origin with heart failure. $J$ Card Fail 2006; 12: 211-19.

21. Schmidt S: Telemedizin und Lebensqualität (Telemedicine and quality of life). Deutsche Medizinische Wochenschrift 2007; 132 442-7.

22. Schmidt S, Sheikzadeh S, Beil B, Patten M, Stettin J: Acceptance of telemonitoring to enhance medication compliance in patients with chronic heart failure. Telemedicine and e-Health 2008; 14(5): 426-33.

23. Schwab J, et al.: Telemedizin in der Kardiologie - Relevanz für die Praxis? Herz 2008; 33: 420-30.
24. Tsuyuki RT, Fradette M, Johnson JA: Multicentre disease management program for hospitalized patients with heart failure: the Review of Education on ACE Inhibitors in Congestive Heart Failure Treatment (REACT) Study. J Card Fail 2004; 10: 473-80.

25. Woodend AK, et al.: Telehome monitoring in patients with cardiac diseases who are at high risk of readmission. Heart \& Lung 2008; 37: $36-45$.

\section{Corresponding author}

Prof. Dr. phil. Silke Schmid

Lehrstuhl Gesundheit und Prävention

Ernst-Moritz-Arndt Universität Greifswald

Institut für Psychologie

Robert-Blum-Str. 13

17487 Greifswald, Germany

silke.schmidt@uni-greifswald.de 


\title{
Home Telemonitoring in Patients With Chronic Heart Failure
}

\author{
A Chance to Improve Patient Care? \\ Silke Schmidt, Andreas Schuchert, Thomas Krieg, Michael Oeff
}

\section{E-REFERENCES}

e1. Antonicelli R, et al.: Impact of telemonitoring at home on the management of elderly patients with congestive heart failure. Journal of Telemedicine and Telecare 2008; 14: 300-5.

e2. Arya A, et al.: Influence of home monitoring on the clinical status of heart failure patients: Design and rationale of the IN-TIME study. Eur J Heart Fail 2008; 10: 1143-8.

e3. Barlow J, et al.: A systematic review of the benefits of home telecare for frail elderly people and those with long term-conditions. J Telemed Telecare 2007; 13: 172-9.

e4. Capomolla S, Febo 0, Ceresa M: Cost/utility ratio in chronic heart failure: comparison between heart failure management program delivered by day-hospital and usual care. J Am Coll Cardiol 2002; 40: 1259-66.

e5. Gattis WA, et al.: Reduction in heart failure events by the addition of a clinical pharmacist to the heart failure management team. Arch Intern Med 1999; 159: 1939-45.

e6. Halimi F, Clementy J, Attuel P, Dessenne X, Amara W; on behalf of the OEDIPE trial investigators: Optimized post-operative surveillance of permanent pacemakers by home monitoring: the OEDIPE trial. Europace 2008; 10: 1392-9.

e7. Heidbüchel $H$, et al.: Potential role of remote monitoring for scheduled and unscheduled evaluations of patients with an implantable defibrillator. Europace 2008; 10: 351-7.

e8. Hersh W: Evidence report telemedicine. US Health Serv Agency, 2006.

e9. Hindricks G, Bauer WJ, Schwab J0: Telemedizin in der Kardiologie. Was bringt die Telekardiologie für Patient und Arzt? Dtsch Arztebl Int 2008; 105: 156-9.

e10. Hing ES, Burt CW, Woodwell DA: Electronic medical record use by office-based physicians and their practices: United States, 2006. Advanced data from vital and health spastics 2006; 393: 1-7.

e11. Linder JA, Bates DW: Electronic health record use and the quality of ambulatory care in the United States. Arch Intern Med 2007; 167: 1400-5.

e12. Mair F, Whitten P: Systematic review of studies of patient satisfaction with telemedicine. British Medical Journal 2000; 320: $517-20$. e13. Martínez-Fernández A, et al.: A systematic review of the literature on home monitoring for patients with heart failure. J Telemed Telecare 2006; 12: 234-41.

e14. Miller EA: Telemedicine and doctor-patient communication: an analytical survey of the literature. Journal of Telemedicine and Telecare 2001; 7: 1-17.

e15. Müller A, et al.: Telemedizin in der Kardiologie - Welche Anwendungen sind reif für die klinische Praxis? Dtsch Med Wochenschr 2008; 133: 2039-44.

e16. Paré G, Jaana M, Sicotte C: Systematic review of home telemonitoring for chronic diseases: the evidence base. J Am Med Inform Assoc 2007; 14: 269-77.

e17. Schmidt S, Koch U: Telemedizin aus medizinpsychologischer Perspektive - Der Einfluss von Telematikanwendungen auf die ArztPatienten-Beziehung. Zeitschrift für Medizinische Psychologie 2003; 12: 105-17.

e18. Schmidt S, Schuchert A: Healthcare research in monitoring with CHS-Patients in European Hospital Healthcare. Campden Media 2009.

e19. Schmidt S: Personalized health monitoring (PHM) — Interdisciplinary research to analyse the relationship between ethics, law and psychosocial as well as medical sciences (PHM-Ethics) 2009.

e20. Schwarz KA, et al.: Telemonitoring of heart failure patients and their caregivers: a pilot randomized controlled trial. Progress in Cardiovascular Nursing 2008; 23: 18-26.

e21. Walsh SH: The clinician's perspective on electronic health records and how they can affect patient care. BJM 2004; 328: 1184-7.

e22. Crossley, GH, et al.: Clinical benefits of remote versus transtelephonic monitoring of implanted pacemakers. J Am Coll Cardiol 2009; 54(22): 2012-9.

e23. Klersy, C., et al.: A meta-analysis of remote monitoring of heart failure patients. J Am Coll Cardiol 2009; 54(18): 1683-94. 